Kathryn K. Lauer MD,*

Lois A. Connolly MD, ${ }^{\dagger}$

William T. Schmeling MD PhD

\title{
Opioid sedation does not alter intracranial pressure in head injured patients
}

Purpose: This study aimed to examine the effects of sedative doses of morphine, fentanyl and sufentanil on intracranial pressure (ICP) in head-injured patients in whom changes in mean arterial pressure (MAP) were minimized.

Methods: Fifteen severely head-injured patients (GSC of $\leq 8$ ) were randomly assigned to receive either fentanyl, sufentanil or morphine, titrating the drug to a maximal $10 \%$ decrease in MAP. The patients were subsequently given an infusion of the same opioid. For four hours, ICP, MAP and heart rate were reconded.

Results: In all groups, there were no increases in ICP. There was a decrease in MAP in the sufentanil group at $10 \mathrm{~min}(P<0.05)$ and $45 \mathrm{~min}$ after the initial opioid bolus. These decreases in MAP were not associated with increases in ICP.

Conclusion: The study suggests that when opioids are titrated in head-injured patients, worsening intracranial pressure can be avoided.

Objectif : Étudier les effets de doses sédatives de morphine, de fentanyl et de sufentanil sur la pression intracrânienne (PIC) chez des traumatisés du crâne dont la pression artérielle moyenne (PAM) r'avait que légèrement varié.

Méthodes : Quinze graves traumatisés du crâne (Échelle de Glasgow $\leq 8$ ) ont été assignés aléatoirement pour recevoir du fentanyl, du sufentanil, ou de la morphine titrés de façon à abaisser la PAM de $10 \%$ ou moins. Les patients ont par la suite reçu une perfusion du même morphinique. Pendant quatre heures, la PIC, la PAM et la fréquence cardiaque étaient enregistrées.

Résultats : La PIC est demeurée inchangée dans tous les groupes. La PAM a baissé dans le groupe sufentanil à la $10^{e}$ minute $(P>0,05)$ et à la $45^{e}$ minute qui ont suivi l'administration du bolus initial. Ces diminutions de la PAM n'étaient pas associées à une augmentation de la PIC.

Conclusion : Cette étude suggère que l'administration titrée de morphiniques à des traumatisés du crâne ne provoque pas de détérioration de la pression intracrånienne.

From the Department of Anesthesiology, Medical College of Wisconsin, ${ }^{\star \dagger}$ Milwaukee, Wisconsin and Zablockj VA Medical Center, Milwaukee, Wisconsin.

Address correspondence to: Kathryn K. Lauer MD, Department of Anesthesiology, Froedtert Memorial Lutheran Hospital, $9200 \mathrm{~W}$. Wisconsin Ave, Milwaukee, WI 53226; Phone: 414-259-2715; Fax: 414-259-1522; E-mail: klauer @ post.its.mcw.edu

Supported in part by medical research funds from the Department of Veterans Affairs.

Accepted for publication May 15, 1997. 


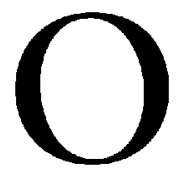
PIOID receptor agonists, including the synthetic opioids fentanyl and sufentanil, are frequently used as anaesthetic adjuncts during the perioperative management of neurosurgical patients. Previous studies have documented that agonists decrease the requirements for volatile anesthetic agents. ${ }^{1-3}$ The volatile anaesthetic agents produce direct cerebral vascular dilatation, resulting in an increase in cerebral blood volume (CBV), and potentially increasing intracranial pressure (ICP). In contrast, opioid agonists are associated with preservation of cerebral vascular autoregulatory responses to changes in $\mathrm{PCO}_{2}$ and mean arterial pressure (MAP)., ${ }^{4,8}$

Recent studies have questioned the use of opioids in patients with compromised intracranial compliance. Milde et $a l^{5}$ demonstrated an increase in cerebral blood flow (CBF) and ICP after the administration of sufentanil to normal dogs. Since this initial study, other conflicting studies in humans and animals have followed ${ }^{6-13}$ Sperry et al ${ }^{14}$ administered bolus injections of fentanyl $\left(3 \mu \mathrm{g} \cdot \mathrm{kg}^{-1}\right)$ or sufentanil $\left(0.6 \mu \mathrm{g} \cdot \mathrm{kg}^{-1}\right)$ in sedative doses to head-injured patients. The administration of either fentanyl or sufentanil was associated with increases in ICP and decreases in systemic MAP of $>10 \%$. The increase in ICP returned to baseline after $30 \mathrm{~min}$. A similar study was performed by Albanese et al..$^{15}$ in which a sufentanil bolus of 1 $\mu \mathrm{g} \cdot \mathrm{kg}^{-1}$ followed by $0.005 \mu \mathrm{g} \cdot \mathrm{kg}^{-1} \cdot \mathrm{min}^{-1}$ infusion was associated with decreases in systemic MAP and increases in ICP.

The purpose of the present investigation was to compare the effects of fentanyl, sufentanil or morphine sedation on alterations in the ICP of headinjured patients while attempting to maintain MAP.

\section{Methods}

After institutional and human research committce approval, 15 severely head-injured patients were randomized to receive either morphine (Group $1, n=5$ ), fentanyl (Group 2, n=5), or sufentanil (Group 3, $n=5$ ) for sedation. Before this study, morphine had been used as the sole opioid in the intensive care unit, and was considered the control agent for study comparison.

\section{Patient selection}

All patients were haemodynamically stable and had been without pharmacological pressor support for two hours before initiation of the study. Patients who were pregnant, were $<16 \mathrm{yr}$ of age, were morbidly obese or had any pre-existent neurological, cardiac, renal or hepatic disease before their head injury were excluded from the study. In our institution, ICP monitoring is reserved for those patients who were head injured, yet failed diuretics and hyperventilation. In all patients, the tracheas were intubated, the lungs mechanically ventilated and hyperventilated to $\mathrm{PaCO}_{2}$ of 25-30 $\mathrm{mmHg}$ as determined by arterial blood gas determination. The lungs were ventilated with a Servo ventilator (Siemens Corporation). All patients had been receiving phenytoin $2 \mathrm{mg} \cdot \mathrm{kg}^{-1} \mathrm{q} 8 \mathrm{~h}$, ranitidine or cimetidine $(50 \mathrm{mg}$ or $300 \mathrm{mg} \mathrm{q} 8 \mathrm{~h}$, respectively, for stress ulcer prophylaxis), midazolam (2-5 $\left.\mathrm{mg} \cdot \mathrm{hr}^{-1}\right)$, and mannitol $\left(0.5-2.0 \mathrm{~g} \cdot \mathrm{kg}^{-1}\right.$, to maintain serum osmolality $300-320 \mathrm{mOsm} \cdot \mathrm{kg}^{-1}$ ). All patients were kept in a 20 head-up position. No patients had received morphine for two hours prior to the initiation of this study. No patients were receiving muscle relaxants at the time of the study.

\section{Monitoring}

All patients were monitored with continuous electrocardiography (Leads II, and modified $\mathrm{V}_{5}$ ) (Marquette Electronics, Milwaukee, WI), pulse oximetry (Ohmeda Corporation, Madison, WI), and intermittent temperature measurements. All patients had indwelling radial artery catheters for direct arterial pressure measurements. All patients had subdural ICP monitors placed electively under local anaesthesia (lidocaine $1 \%$ ) by neurosurgeons in the intensive care unit before the initiation of the study. The ICP monitoring system was a Camino subdural catheter (OLM Intracranial Pressure Monitor, Camino Laboratories, San Diego, $\mathrm{CA}$ ) coupled to a Marquette Series 7000 monitor via a dual pressure Marquette module (Marquette Electronics, Milwaukee WI). The Camino catheter system uses a subarachnoid bolt and miniature ICP transducer.

\section{Clinical protocol}

In all groups, an opioid loading dose was administered by timed, slow, continuous intravenous administration over a five minute interval. The infusion was continuously adjusted to a targeted alteration in systemic mean arterial pressure of not more than $5 \%$ from preinfusion control value. If the blood pressure changed by $5 \%$ from the control value, the opioid infusion was stopped. This dose was subsequently calculated in terms of a $\mathrm{mg} \cdot \mathrm{kg}^{-1}$ dose for morphine, or $\mu \mathrm{g} \cdot \mathrm{kg}^{-1}$ dose for fentanyl or sufentanil. This dose was then used as the basis to initiate a continuous infusion which was maintained for four hours. During this time, ICP, MAP, and heart rate were continuously monitored and recorded every 15 min for the first two hours, and then every $30 \mathrm{~min}$ for the last two hours of the study. Cerebral perfusion pressure (CPP) was calculated as (MAP-ICP) for all the data points available. 


\section{Statistical analysis}

Data within and between groups before and during drug administration were analyzed with a repeated measures analysis of variance (ANOVA) followed by application of Bonferroni-adjusted paired $t$ tests. Changes from control within a condition or between conditions were considered statistically significant when $P$ was $<0.05$. The SAS software package was utilized for statistical analysis. ANOVA was used to analyze differences in demographic data. All data are expressed as means \pm standard error of the mean. Analysis of relationship between MAP and ICP was performed with both a Spearman Rank Order Correlation and Pearson Product Correlation using Sigma Stat statistical software.

\section{Results}

\section{Demographic data}

Patient age ranged from 16 to $52 \mathrm{yr}$. All three groups had Glasgow Coma Scale scores representing severe head trauma $(\mathrm{GCS}<8)$. All patients had $\mathrm{PCO}_{2}$ values between 26 and $29 \mathrm{mmHg}$. There were no differences between groups except for weight, with the sufentanil group being slightly heavier (ANOVA, $P=0.05$ ) (Table 1).

\section{Haemodynamic and icp response to opioids}

The mean doses of fentanyl, morphine and sufentanil in each group are listed in Table II. The average initial bolus doses were $2.98 \pm 1.73 \mu \mathrm{g} \cdot \mathrm{kg}^{-1}$ for the fentanyl group, $0.07 \pm 0.03 \mathrm{mg} \cdot \mathrm{kg}^{-1}$ for the morphine group, and $0.37 \pm 0.13 \mu \mathrm{g} \cdot \mathrm{kg}^{-1}$ for the sufentanil group.

Baseline MAP in the three groups was not different (morphine $90.8 \pm 6.9 \mathrm{mmHg}$, fentanyl $90.8 \pm 4$ $\mathrm{mmHg}$, sufentanil $98.4 \pm 5.8 \mathrm{mmHg}, P<0.05$ ). The recorded MAPs during this study were not different

TABLE I Dcmographic Data

\begin{tabular}{lccc}
\hline & Morphine & Fentanyl & Sufentanil \\
\hline & Mean \pm SD & Mean \pm SD & Mean \pm SD \\
Age (yr) & $21 \pm 6$ & $22 \pm 9$ & $35 \pm 12$ \\
Glasgow Coma Score & $6 \pm 2$ & $5 \pm 2$ & $6 \pm 2$ \\
Weight $(\mathrm{kg})$ & $73 \pm 6$ & $59 \pm 12$ & $84 \pm 21$ \\
$\mathrm{PCO}_{2}$ & $28 \pm 1$ & $26 \pm 4$ & $29 \pm 2$ \\
pH (range) & $7.45-7.56$ & $7.49-7.58$ & $7.49-7.51$ \\
\hline
\end{tabular}

TABLE II Opioid Doses Administered to ICP Patients (Mean \pm SD)

\begin{tabular}{lll}
\hline & Bolus & Infusion \\
\hline Fentanyl & $2.98 \pm 1.73 \mu \mathrm{g} \cdot \mathrm{kg}^{-1}$ & $1.63 \pm 0.48 \mu \mathrm{g} \cdot \mathrm{kg} / \mathrm{h}^{-1}$ \\
Morphine & $0.07 \pm 0.03 \mathrm{mg} \cdot \mathrm{kg}^{-1}$ & $0.03 \pm 0.02 \mu \mathrm{mg} \cdot \mathrm{kg} / \mathrm{h}^{-1}$ \\
Sufentanil & $0.37 \pm 0.13 \mu \mathrm{g} \cdot \mathrm{kg}^{-1}$ & $0.33 \pm 0.16 \mu \mathrm{kg} / \mathrm{h}^{-1}$ \\
\hline
\end{tabular}

from baseline throughout the four hour study period except in the sufentanil group at 10 min (mean $80.6 \pm$ $12.1 \mathrm{mmHg}, P<0.05$ ) and $45 \mathrm{~min}$ after bolus administration (mean $82.4 \pm 8.8$ ). (Figure 1) The MAP was lower than baseline at these times.

Baseline ICPs were not different among groups (morphine $14.6 \pm 5 \mathrm{mmHg}$, fentanyl $13.6 \pm 3 \mathrm{mmHg}$, sufentanil $18.2 \pm 3$ ). In addition, the ICPs did not change from baseline in any group. The fentanyl-sedated patients had reduced ICP at 150 and 180 min compared with the morphine- and sufentanil-sedated patients. (Figure 2).

Cerebral perfusion pressure was not different from baseline in any of the three groups. The fentanyl patients had a lower CPP than morphine at $60 \mathrm{~min}$ utes, and was statistically lower than both morphine and sufentanil at 75 minutes (Figure 3 ).

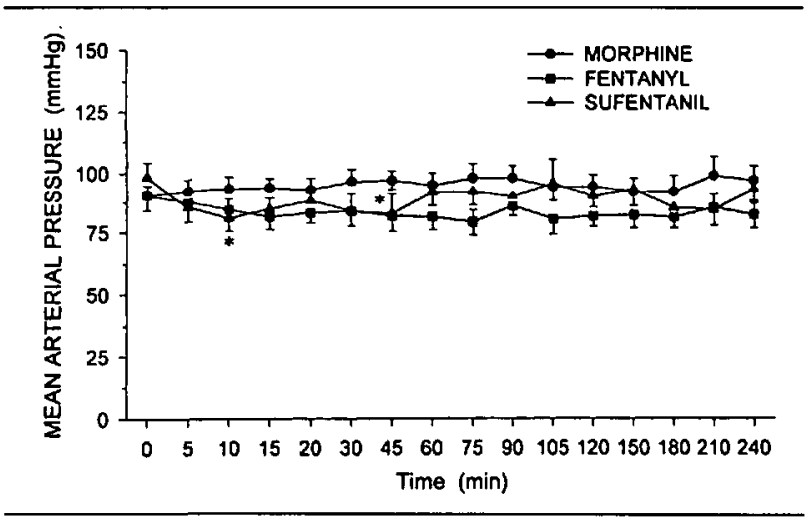

FIGURE 1 The effect of morphine, fentanyl or sufentanil sedation on mean arterial pressure (values are mean $\pm S E M$ ).

${ }^{*}=$ statistically different from baseline control $(P<0.05)$

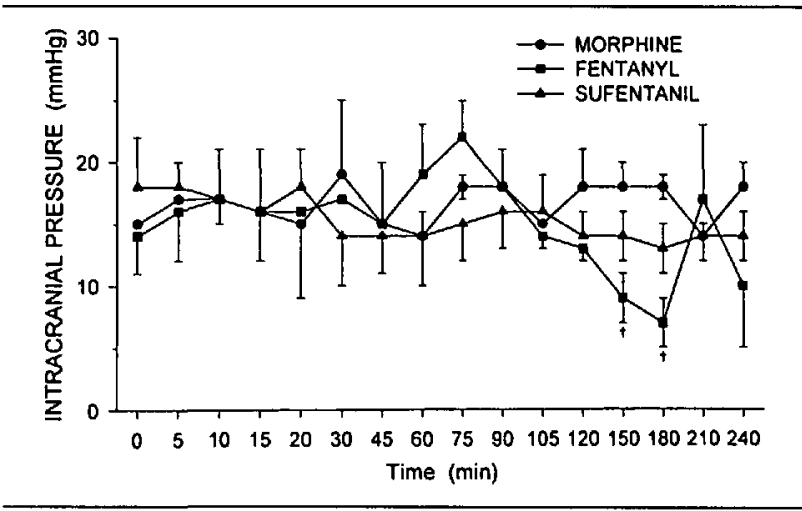

FIGURE 2 The effect of morphine, fentanyl or sufentanil sedation on mean intracranial pressure.

$+=$ statistically different from both morphine and sufentanil $(P<0.05)$ 


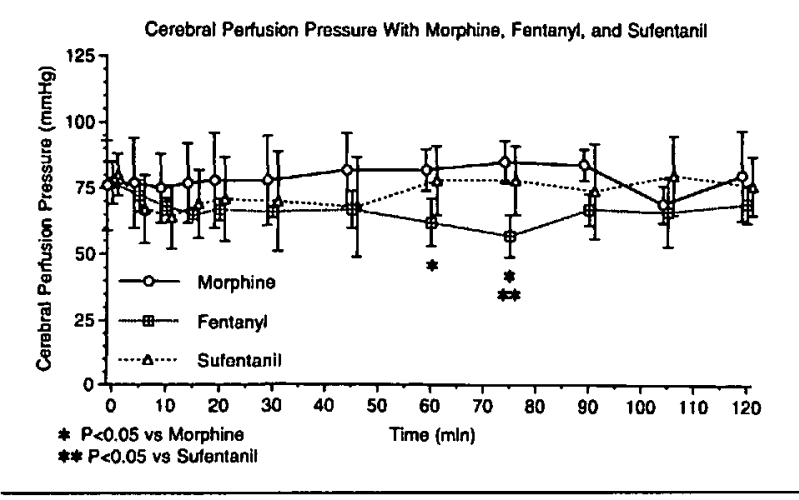

FIGURE 3 The effect of morphine, fentanyl or sufentanil sedation on cerebral perfusion pressure

+ = staristically different from morphine

t statistically different from morphine and sufentanil

The relationship between ICP and MAP was analyzed by Spearman Rank Order correlation and Pearson Product Moment correlation. There was no relationship between ICP and MAP in the patients sedated with morphine. Both fentanyl and sufentanil demonstrated a positive correlation, meaning both variables increased together (Figure 4$)(P<0.01)$.

Baseline heart rates were not different. Heart rates were lower in the sufentanil group than in the fentanyl groups at all times except baseline and at $75 \mathrm{~min}$ and were different from morphine at 105, 120, 180 and $240 \mathrm{~min}$.

\section{Discussion}

In the present investigation, changes in systemic MAP for each patient were minimized in order to examine the effect of a sedative dose of opioid on ICP alterations in patients with pre-existing elevation of ICP. The initial sedative dose was determined by a maximal $5 \%$ decrease in systemic MAP. The patients were then given an opioid infusion, with the dose calculated from the sedative amount that just resulted in this alteration in systemic MAP. The results demonstrate no increases in ICP in the morphine, fentanyl or sufentanil groups.

This study was designed to maintain MAP close to baseline. This was accomplished in all but the sufentanil group in which at 10 and 45 min post-bolus the MAP decreased below baseline. The magnitude of the changes of MAP were small, but when related to the alterations in ICP, there was a tendency for an increase or decrease in MAP to be met with the same change in ICP in the fentanyl and sufentanil sedated patients. This is in conflict with other studies of opioids $^{6,14-16,25,26}$ when the administration of opioids caused a decrease in MAP which was met with an increase in ICP. Werner et al., ${ }^{24}$ for example, developed worsened ICP in patients given sufentanil if their MAP decreased $>10 \mathrm{mmHg}$. In his study, the baseline ICP levels were low $(<3)$, but this study had patients with Glasgow Coma Scales of $<6$. In these studies, the range of baseline ICPs were between 0-12 $\mathrm{mmHg}$ (in those that reported their baseline ICP) with the exception of the study by Albanese. ${ }^{15}$

Bouma et al..$^{18}$ evaluated intracranial dynamics with CBF measurement and intraventricular compliance evaluations from intraventricular catheters, and two groups of patients emerged. Patients without intact autoregulation had intracranial pressures that varied directly with MAP. The other group, patients with intact autoregulation, developed large increases in ICP with modest lowering of MAP, though an increase in MAP did not necessarily increase ICP. Perhaps patients with lower baseline ICPs, as in these studies, maintain autoregulation better. Weinstable ${ }^{22}$ had a group of patients with ICPs of $\geq 20 \mathrm{mmHg}$ and did not find elevations of ICP in response to decreases in MAP when given sufentanil. In our study, the baseline ICPs were higher, and loss of autoregulation is consistent with the overall relationship of MAP and ICP changes reported in this study.

The maintenance of MAP could have been accomplished by pressor agents. In the present investigation, pressor agents were not used to maintain systemic MAP. In a study by Mayberg et al. ${ }^{16}$ when MAP was supported by phenylephrine, the increase in ICP associated with the administration of alfentanil was ameliorated. Here, no pressor agents were utilized in order to evaluate the effects of the opioid agonists on ICP independently.

Minute ventilation was kept constant to maintain hypocarbia. Whether the use of hyperventilation worsened or improved ICP in this study is unknown as there was no prehyperventilation baseline with which to compare it. Previous studies that evaluated the effect of opioids on ICP varied in the use of hyperventilation. The patients were not standardized to receive nondepolarizing muscle relaxants. It is our preference to be able to continually follow patients with neurological examinations.

The average dose of fentanyl used in this study $(3 \pm$ $1.7 \mu \mathrm{g} \cdot \mathrm{kg}^{-1}$ ) was similar in magnitude to the doubleblind bolus $\left(3 \mu \mathrm{g} \cdot \mathrm{kg}^{-1}\right)$ given to head-injured patients by Sperry et al..$^{14}$ The average dose of sufentanil in our study was $0.38 \pm 1.3 \mu \mathrm{g} \cdot \mathrm{kg}^{-1}$ whereas Sperry et al. administered $0.6 \mu \mathrm{g} \cdot \mathrm{kg}^{-1}$ sufentanil. All patients received individualized, not uniform, doses of opioids to control systemic MAP. Varying the dose of opioids to a physiological target endpoint is, in general, the clinical paradigm most commonly employed. However, the endpoint in a head- 
injured population in which the patients' tracheas are intubated and their lungs mechanically ventilated is not precise. In the current investigation, the target endpoint was a $<5 \%$ change in MAP. In a recent study, it was demonstrated that sufentanil, at a lower dose than that used on our study $\left(0.1 \mu \mathrm{g} \cdot \mathrm{kg}^{-1}\right)$, combined with hyperventilation, induced a decrease in spectral EEG power into the delta range. ${ }^{21}$ Consequently, a $0.38 \mu \mathrm{g} \cdot \mathrm{kg}^{-1}$ sufentanil should have been an adequate sedative dose.

In summary, the present investigation suggests that slow titrated administration of fentanyl, sufentanil or morphine with subsequent continued infusion preserves systemic arterial pressure without elevating ICP.

\section{Acknowledgments}

The authors would like to thank Carole Panaro, Dave Schwabe and Nordeana Nimphius for technical help with this manuscript, and Dr. Sanford Larson for his cooperation and support.

\section{References}

1 Heckler BR, Lake CL, DiFazio CA, Moscicki JC, Engle $J S$. The decrease of the minimum alveolar anesthetic concentration produced by sufentanil in rats. Anesth Analg 1983; 62: 987-90.

2 Murphy MR, Hug CC Jr. The anesthetic potency of fentanyl in terms of its reduction of enflurane MAC. Anesthesiology 1982; 57: 485-8.

3 Hall RI, Szlam F, Hug CC Jr. The enflurane-sparing effect of alfentanil in dogs. Anesth Analg 1987; 66: 1287-91.

4 McPherson RW, Traystman RJ. Fentanyl and cerebral vascular responsivity in dogs. Anesthesiology 1984; 60: 180-6.

5 Milde LN, Milde JN, Gallagher WJ. Effects of sufentanil on cerebral circulation and metabolism in dogs. Anesth Analg 1990; 70: 138-46.

$6 \operatorname{Marx} W$, Shah $N$, Long $C$, et al. Sufentanil, alfentanil, and fentanyl: impact on cerebrospinal fluid pressure in patients with brain tumors. Journal of Neurosurgical Anesthesiology 1989; 1: 3-7.

7 Mayer N, Weinstabl C, Podreka I, Spiss CK. Sufentanil does not increase cerebral blood flow in healthy human volunteers. Anesthesiology 1990; 73: 240-3.

8 Stephan H, Gröger $P$, Weyland $A$, Hoeft $A$, Sonntag $H$. Effects of high-dose sufentanil- $\mathrm{O}_{2}$ anesthesia on cerebral blood flow, metabolism, and the cerebrovascular response to carbon dioxide in man. (German) Anaesthetist 1991; 40: 153-60.

9 Werner C, Hoffman W, Baughman VL, Albrecht RF, am Esch JS. Effects of sufentanil on cerebral blood flow, cerebral blood flow velocity, and metabolism in dogs. Anesth Analg 1991; 72: 177-81.
10 From RP, Warner D, Todd MM, Sokoll MD. Anesthesia for craniotomy: a double-blind comparison of alfentanil, fentanyl, and sufentanil. Anesthesiology 1990; 73: 896-904.

11 Weinstabl C, Mayer $N$, Spiss $C K$. Sufentanil decreases cerebral blood flow velocity in patients with elevated intracranial pressure. Eur J Anaesthesiol 1992; 9: 481-4.

12 Hörmann C. Langmayr J, Schalow S, Benzer A. Low-dose sufentanil increases cerebrospinal fluid pressure in human volunteers. J Neurosurg Anesthesiol 1995; 7: 7-11.

13 Herrick $L A$, Gelb $A W$, Manninen PH, Reichman $H$, Lownie $S$. Effects of fentanyl, sufentanil, and alfentanil of brain retractor pressure. Anesth Analg 1991; 72: 359-63.

14 Sperry $R J$, Bailey $P L$, Reichman $M V$, Peterson JC, Petersen $P B$, Pace NL. Fentanyl and sufentanil increase intracranial pressure in head trauma patients. Anesthesiology 1992; 77: 416-20.

15 Albanese J. Durbec O, Viviand X, Potie F, Alliez B, Martin $C$. Sufentanil increases intracranial pressure in patients with head trauma. Anesthesiology 1993; 79: 493-7.

16 Mayberg TS, Lam A, Eng CC, Laohaprasit V, Winn HR. The effect of alfentanil on cerebral blood flow velocity and intracranial pressure during isoflurane-nitrous oxide anesthesia in humans. Anesthesiology 1993; 78: 288-94.

17 Marmarou $A$. Increased intracranial pressure in head injury and influence of blood volume. J Neurotrauma 1992; 9: S327-32.

18 Bouma GJ, Muizelaar JP, Bandoh K, Marmarou A. Blood pressure and intracranial pressure-volume dynamics in severe head injury: relationship with cerebral blood flow. J Neurosurg 1992; 77: 15-9.

19 McIntosh TK, Hayes RL, DeWitt DS, Agura V, Faden $A I$. Endogenous opiods may mediate secondary damage after experimental brain injury. Am J Physiol 1987; 253: E565-74.

20 Lyeth $B G$, Hayes $R L$. Cholinergic and opiod mediation of traumatic brain injury. J Neurotrauma 1992; 9: S463-74.

21 Matteo RS, Ornstein E, Schwartz $A E$, Young $W L$, Weinstein J, Cain CF. Effects of hypocarbia on the pharmacodynamics of sufentanil in humans. Anesth Analg 1992; 75: 186-92.

22 Weinstabl C, Mayer N, Richling B, Czech T, Spiss CK. Effect of sufentanil on intracranial pressure in neurosurgical patients. Anaesthesia 1991; 46: 837-40.

23 Albanese J, Durbec O, Viviand X, Potic F, Alliez B, Martin $C$. Sufentanil increases intracranial pressure in patients with head trauma. Anesthesiology 1993; 79: 493-7.

24 Werner C, Kochs E, Bause H, Hoffman WE, Scbulte am Esch J. Effects of sufentanil on cerebral hemodynamics and ultracranial pressure in patients with brain injury. Anesthesiology 1995; 83: 721-6. 